\title{
Familiality and Diagnostic Patterns of Subphenotypes in the National Institutes of Mental Health Bipolar Sample
}

\author{
Erika H. Saunders, ${ }^{1,2} *$ Laura J. Scott, ${ }^{3}$ Melvin G. McInnis, ${ }^{1,2}$ and Margit Burmeister ${ }^{1,2,4,5}$ \\ ${ }^{1}$ University of Michigan Depression Center, Ann Arbor, Michigan \\ ${ }^{2}$ Department of Psychiatry, University of Michigan, Ann Arbor, Michigan \\ ${ }^{3}$ Department of Biostatistics, University of Michigan, Ann Arbor, Michigan \\ ${ }^{4}$ Molecular \& Behavioral Neuroscience Institute, University of Michigan, Ann Arbor, Michigan \\ ${ }^{5}$ Department of Human Genetics, University of Michigan, Ann Arbor, Michigan
}

\begin{abstract}
Bipolar-related subphenotypes that cluster within families may help identify subsets of patients that are more genetically homogeneous. Environmental or assessment factors that segregate by family may influence estimates of familiality. We aimed to determine familiality of subphenotypes of bipolar disorder (BP), accounting for effects of age, sex, diagnosis, and site/wave of ascertainment. We studied 589 sibships with 1416 siblings affected with bipolar I (BPI), schizoaffective disorder, bipolar type (SAB), bipolar II (BPII), or recurrent unipolar depression (RUDD). Sibships were from families with $\geq 2$ BPI cases collected by the NIMH Bipolar Genetics Initiative (NIMHBGI). Rapid cycling showed the strongest evidence for familiality [odds ratio $(\mathrm{OR})(95 \% \mathrm{CI})=$ $\left.2.02(1.43,2.85), P=6.0 \times 10^{-5}\right]$ in a model including age, sex, diagnosis, and site/wave of ascertainment. Additional significantly familial traits were comorbid alcohol abuse/dependence $\left(P=2 \times 10^{-4}\right)$ and comorbid panic disorder $\left(P=8 \times 10^{-3}\right)$, as well as psychosis, suicidal thoughts, and rapid mood switching $\left(P=6 \times 10^{-3}-0.03\right)$. Omission of the effect of site/wave of ascertainment from the model inflated the significance level of the apparent familial association of almost all subphenotypes from one to four orders of magnitude. We have found evidence of familiality for subphenotypes of BP. In multicenter samples, familiality may be overestimated if variability in diagnosis of subphenotypes between site/wave of ascertainment is not considered. () 2007 Wiley-Liss, Inc.
\end{abstract}

KEY WORDS: genetics; phenomenology; epidemiology; subtype

This article contains supplementary material, which may be viewed at the American Journal of Medical Genetics website at http://www.interscience.wiley.com/jpages/1552-4841/suppmat/ index.html.

Erika H. Saunders and Laura J. Scott, contributed equally to the manuscript.

Grant sponsor: R25MH063742; Grant sponsor: Rachel Upjohn Clinical Scholars Program; Grant sponsor: Heinz C. Prechter Pediatric Bipolar Scholars Program.

*Correspondence to: Erika H. Saunders, M.D., Department of Psychiatry Rachel Upjohn Building, University of Michigan, 4250 Plymouth Road, Room 2201, Ann Arbor, MI 48109.

E-mail: esaunder@umich.edu

Received 17 September 2006; Accepted 2 April 2007

DOI 10.1002/ajmg.b.30558
Please cite this article as follows: Saunders EH, Scott LJ, McInnis MG, Burmeister M. 2008. Familiality and Diagnostic Patterns of Subphenotypes in the National Institutes of Mental Health Bipolar Sample. Am J Med Genet Part B 147B:18-26.

\section{INTRODUCTION}

Bipolar disorder (BP) affects approximately $1 \%$ of the population [Olfson et al., 1997]; it is ninth on the World Health Organization [WHO, 2001] list of leading causes of years of life lived with disability for persons ages 15-44. BP has an estimated heritability of 59-87\% [Smoller and Finn, 2003] with concordance rates of $67 \%$ in monozygotic twins and $20 \%$ in dizygotic twins and first-degree relatives [Bertelsen et al., 1977]. Several genome-wide linkage scans have been performed in the past decade, and three recent meta-analyses in overlapping samples have shown evidence for linkage on chromosome $9 p$ and $10 q$ [Segurado et al., 2003], 13q and $22 q$ [Badner and Gershon, 2002], and 6q and 8q [McQueen et al., 2005]. Several genes have shown associations to the BP phenotype [Hayden and Nurnberger, 2006]. The fact that no one gene or region has been consistently implicated may reflect underlying genetic heterogeneity of BP and/or lack of adequate power to detect weak effects.

The diagnosis of $\mathrm{BP}$ is made using operational diagnostic criteria defined by DSM-IV [APA, 2000]. These criteria reflect symptoms relating to disordered mood and affect. While there may be a unifying theme of increased energy, grandiosity, and pressured speech in mania, the hallmark of bipolar I disorder (BPI), there is substantial variability across patients in associated clinical phenomena such as psychosis, mixed states, rapid cycling, panic disorder, alcoholism, and suicide attempts. Several of these phenomena or subphenotypes appear to cluster in BP families, suggesting families with different subphenotypes may have different genetic etiologies [Potash et al., 2000, 2001, 2003; MacKinnon et al., 2002, 2003a,b; Schulze et al., 2006]. Subphenotypes in the current context refer to comorbid diagnoses or illness-related phenomena. They are not endophenotypes, the manifestation of which is independent of the illness state. Less is known about the familiality of irritable mood in mania, mixed mania (dysphoric mania), and depression-related subphenotypes within BP. Factor analyses have identified dysphoric mood, psychosis, increased hedonic function, and irritable aggression as separate facets of mania [Cassidy et al., 1998; Swann et al., 2001; Sato et al., 2002]. These factors showed inter-episode constancy in individuals [Cassidy et al., 2002; Sato et al., 2003]. Atypical depression, defined by symptoms of mood reactivity, sensitivity to interpersonal rejection, increased appetite, hypersomnia, and leaden paralysis, has been associated with BP [Parker et al., 2002]. Familiality studies of subtypes in 
major depressive disorder have been inconsistent [Sullivan et al., 2002; Korszun et al., 2004].

In this study, we analyzed sibships from 589 BP families from the National Institutes of Mental Health Bipolar Genetics Initiative [NIMHBGI, 1997] and identified phenotypes, both comorbidities and specific symptoms of BP, that show evidence of familiality in sibships from the NIMHBGI data. Inclusion of site and wave of collection in the analysis greatly reduced evidence of familality for many of the subphenotypes. Our results indicate that while familial subtypes of $\mathrm{BP}$ may exist, familiality may be overestimated if variability in the prevalence of subphenotypes and diagnosis of certain features of $\mathrm{BP}$ between collection site and wave of ascertainment is not considered.

\section{METHODS AND MATERIALS}

\section{Subjects}

Phenotypic data from the NIMHBGI were used in this analysis. This multicenter collaborative effort gathered phenotypic and genotypic data from individuals in families with BP. Families were recruited if they had a BPI proband and a first degree relative with BPI or schizoaffective disorder, bipolar type (SAB). In waves 1 and 2 (W1-2), recruitment at four sites focused on large families [NIMHBGI, 1997]. Recruitment at 10 sites in waves 3 and 4 (W3-4) targeted sibling pairs [Dick et al., 2003]. There were four common sites between the W1-2 and W3-4 collections.

Subjects were interviewed with the Diagnostic Interview for Genetic Studies (DIGS) [Nurnberger et al., 1994]. At each site, diagnoses were determined through a best-estimate process involving review by two clinicians who did not participate in the interview. We used previously defined hierarchical models to define affectation status [NIMHBGI, 1997]. Model 1 was defined as BPI or SAB and Model 3 was defined as Model 1 plus bipolar II disorder (BPII) or recurrent unipolar depressive disorder (RUDD). A Model 1 or 3 sibship was defined as a sibship with at least two full siblings meeting the model criteria. For each family, if the sibship with the proband met the Model 1 criteria it was selected ( $n=497$ sibships); otherwise a sibship without the proband that met that Model 1 criteria was selected ( $\mathrm{n}=31$ sibships). For families without a Model 1 sibship, a sibship with a BPI or SAB individual that met the Model 3 criteria was selected with preference given to those with a BPI individual and then to those with the largest number of individuals ( $\mathrm{n}=61$ sibships).

\section{Subphenotype Definition}

Subphenotypes were defined by the presence of comorbid disorder or the presence of a specific symptom (Table II). Comorbid alcohol abuse or dependence included diagnostic codes 305.00 (alcohol abuse) or 303.90 (alcohol dependence). Comorbid panic disorder was identified by diagnostic codes 300.01 (panic disorder without agoraphobia) or 300.21 (panic disorder with agoraphobia). Features of psychosis, mania, suicidality, and depression were determined by answers to questions in the DIGS. Psychosis is defined as the identified presence of delusions or hallucinations during an episode of depression or mania. Manic episodes were diagnosed using DSM criteria, and further characterized by the quality of the mood (irritable or elated). A mixed episode was defined by the presence of five or more concurrent depressive symptoms during a manic episode. Rapid cycling was defined by the report of at least four different mood episodes with periods of being well in-between occurred within 1 year, and rapid mood switching was defined by mood fluctuation that was reported to occur over hours or days. Suicidal thoughts were defined as presence of suicidal thoughts during a depressive episode, and a suicide attempt was defined as any reported suicide attempt. Individual depressive symptoms were defined by answering yes to any question about mood worse in the morning, insomnia, hypersomnia, decreased or increased appetite, lethargy or restlessness in a major depressive episode (MDE). Subphenotypes of catatonia and unipolar mania were excluded from analysis due to a prevalence of less than 0.1 in this sample.

\section{Statistical Analysis}

We excluded individuals missing data on age from all analysis. We estimated the subphenotype prevalence per collection site/wave from BPI individuals in sibships that met Model 1 criteria. Using logistic regression, we tested for heterogeneity of subphenotype prevalence between different combinations of wave and site: between W1-2 and W3-4 for the four sites with collections in both sets of waves using a model that contained variables for three of the four sites and a variable for wave of collection, between sites within W1-2, between sites within W3-4, and between all wave/site collections. We used generalized estimating equations (GEE) [Liang and Zeger, 1986] to account for the correlation between siblings.

We estimated the family clustering as expressed by the familial OR using alternating logistic regression (ALR) [Carey et al., 1993]. A positive familial OR indicates increased odds of concordant affection status between family members given adjustment for individual level covariates. Unlike analyses that use the proband affection status to predict the affection status of siblings or other family members [MacKinnon et al., 2002], for sibships ALR treats all siblings equally and allows for inclusion of covariates for every sibling. ALR alternates between estimation of the effect of the individual level covariates using the familial OR as a measure of the withinfamily correlation and estimation of the familial OR from family member pairs given the estimation of the individual level covariates. We included the covariates of age, sex, diagnosis, and collection site/wave (each site/wave combination separately) as specified. We tested for between-wave heterogeneity of familial ORs using a $\chi^{2}$ goodness-of-fit test [Reis et al., 1999].

\section{RESULTS}

For each affection status model, we selected one sibship containing a minimum of two BPI/SAB individuals for Model 1 and one BPI or SAB individual for Model 3 from waves 1-4 (W1-4) NIMHGBI families. This selection scheme results in 528 Model 1 sibships with 1151 individuals (BPI and SAB) and 589 Model 3 sibships with 1416 individuals (BPI, SAB, BPII, and RUDD) (Table I). Almost all of the participants selfidentified as having white ethnicity (94\%). The mean study age in the combined W1-4 sample for both Models 1 and 3 was $41 \pm 12$ years and the females comprised 61 and $63 \%$ of individuals, respectively (Table I). Most sibships contained two individuals, $84 \%$ for Model 1 and $70 \%$ for Model 3 . Consistent with the recruitment of larger families in W1-2, W1-2 had more sibships with $>2$ individuals than W3-4. Within Model 1, 95\% of individuals were affected with BPI and within Model 3, $81 \%$ of individuals were affected with BPI.

The prevalence of the subphenotypes varied between sites and between waves at the same site (Table II). Of subphenotypes considered, mania with irritable mood exhibited the lowest median prevalence $(0.12)$ and psychosis the highest (0.76). The variability by wave, that is the variability between W1-2 collection and W3-4 collection at the 4 sites that participated in both collections, was significant for 9 of the 16 subphenotypes and varied most substantially for mixed mania and panic (Table III). There was little variability in subphenotype prevalence across sites for W1-2. For W3-4, all 


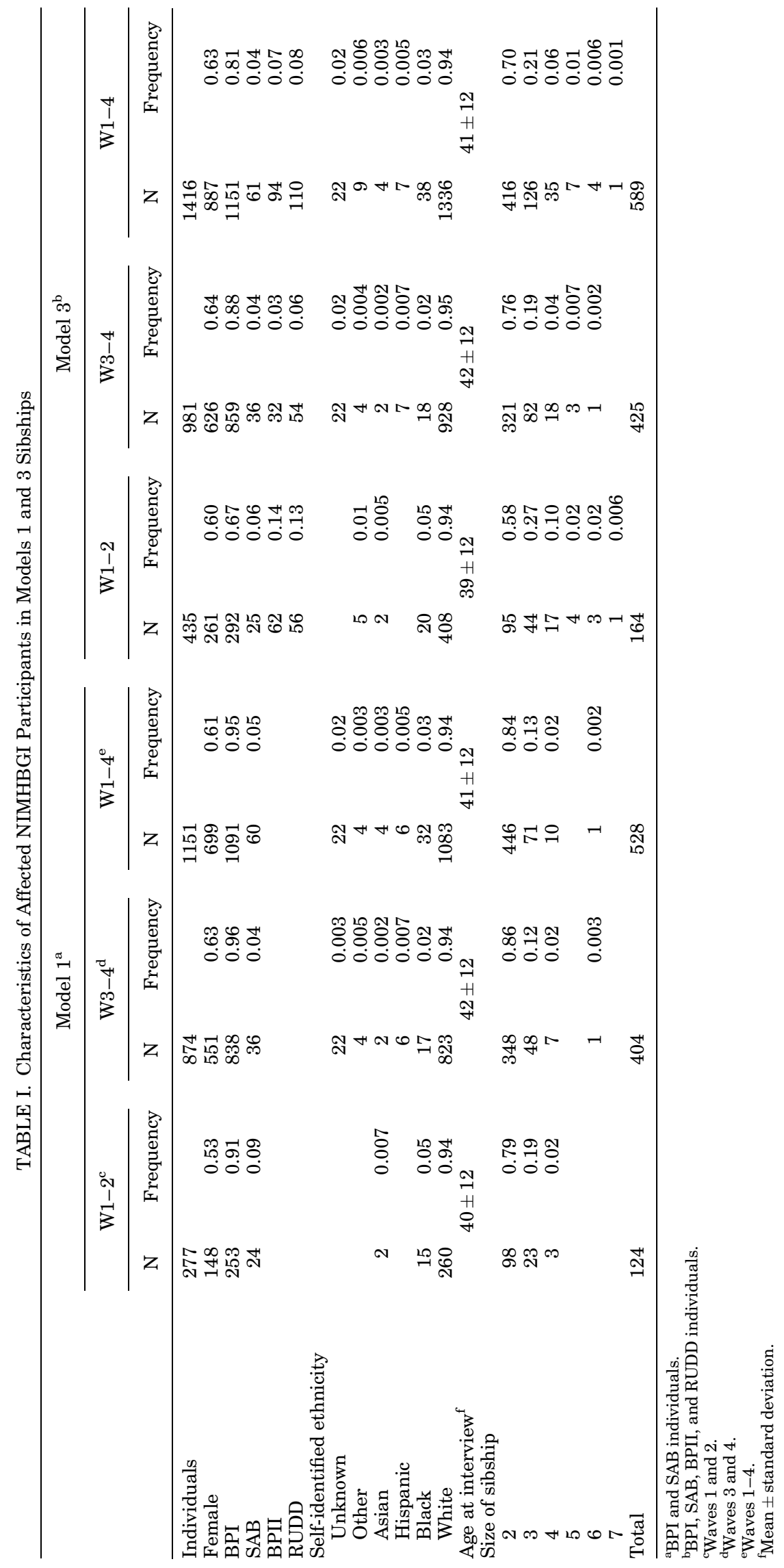


subphenotypes except suicidal thoughts, suicide attempts, mania with irritable mood, decreased appetite and increased appetite in MDE varied significantly (Table III). When subphenotype prevalence was tested across all sites and waves, all subphenotypes except for suicide attempts, decreased appetite and increased appetite in MDE varied significantly and 9 of 16 subphenotypes had $P$-values $<1 \times 10^{-3}$ (Table III). We observed the least variation in prevalence across all sites/ waves of collection for decreased appetite in MDE (0.42-0.58, $P=0.70$ ) and the greatest variability in mood worse in the AM in $\operatorname{MDE}\left(0.15-0.64, P=2 \times 10^{-11}\right)$. Symptoms required for an episode of mania and depression were analyzed using the same method. Consistent with the use of consensus diagnostic criteria across sites, there was much less variation among sites for these core phenotype symptoms than for the subphenotypes. Only 2 of 20 symptoms had a $P$-value $<1 \times 10^{-3}$ (data not shown).

We observed significant familial ORs for many of the BP subphenotypes in both Models 1 and 3 . In the context of sibships, the familial odds ratio (OR) is the factor by which the risk to an individual is increased if a sibling is affected rather than unaffected. In Model 3 sibships rapid cycling [OR $\left.(95 \% \mathrm{CI})=2.02(1.43,2.85), P=6 \times 10^{-5}\right]$, comorbid alcohol abuse or dependence $[\mathrm{OR} \quad(95 \% \mathrm{CI})=1.83 \quad(1.33,2.51)$, $\left.P=2 \times 10^{-4}\right]$ and comorbid panic disorder [OR $\left.(95 \% \mathrm{CI})=1.75(1.16,2.66), P=8 \times 10^{-3}\right]$ showed the strongest evidence of aggregation after adjustment for covariates including site (Table IV). These traits were also significant in Model 1. Psychosis, rapid mood switching, and suicidal thoughts also showed significant aggregation within sibships $(P$-value $<0.05)$ for Models 1 and 3 before and after adjustment for covariates (Table IV, Fig. 1). Additionally, suicidal attempts in Model 1 were significantly aggregated within sibships $(P$-value $=0.02)$. The inclusion of the covariates age, sex, diagnosis, and site of interview in the analysis of the familial OR decreased the OR and often greatly reduced the significance of the results. In almost all models, this decrease was due primarily to inclusion of the site/wave of interview variable (Table IV, Fig. 1). Many subphenotypes did not show evidence of significant familiality after adjustment for covariates: in Model 1 mixed mania, hypersomnia, in Model 3 suicide attempts, and in Models 1 and 3 mood worse in the AM, insomnia and restlessness (Table IV, Fig. 1). Mania with irritable mood, mixed mania (Model 3), hypersomnia (Model 3), decreased appetite and increased appetite in depression, and lethargy in depression did not show significant familiality (Table IV, Fig. 1).

We performed separate analyses for familiality in W1-2 and W3-4 samples (Tables SI and SII). For all but psychosis, the W1-2 and W3-4 had similar ORs. For psychosis the OR was significantly higher in the W3-4 sample $[\mathrm{OR}=2.89,95 \% \mathrm{CI}$ $(1.76,4.73)]$ than in the W $1-2$ sample $[\mathrm{OR}=0.76,95 \% \mathrm{CI}(0.41$, $1.42)]\left(P\right.$-value for OR heterogeneity $\left.=1 \times 10^{-3}\right)$.

\section{DISCUSSION}

$\mathrm{BP}$ has been studied primarily as a single phenotype, and as of yet, few if any predisposing genetic variants have been consistently identified. Detection of phenotypes that cluster within families may lead to the identification of more homogeneous subsets which may in turn increase power to detect genetic variants that predispose to disease. The core symptoms of BP, mania and depression, have been reliably established, but other symptoms and comorbidities vary in prevalence among bipolar individuals [Alda, 2004].

We have observed familiality of comorbid alcohol abuse or dependence, comorbid panic disorder, psychosis, rapid cycling and rapid mood switching, suicidal thoughts and suicide attempts. Our findings were similar in Models 1 and 3 sibships, indicating inclusion of individuals affected with related disorders (BPII and RUDD) did not significantly reduce subphenotype familiality in sibships with one or more BP individuals. We have analyzed a substantially larger collection of families (528 families for Model 1 and 589 families for Model 3) than previous studies [MacKinnon et al., 2002, 2003a; Schulze et al., 2006; Potash et al., 2003]. Our positive findings of familial aggregation concur with previous reports of comorbid panic disorder [MacKinnon et al., 2002; Schulze et al., 2006], psychosis [Potash et al., 2003; Schulze et al., 2006], rapid cycling and rapid mood switching [MacKinnon et al., 2003a], and suicidality within BP families [Potash et al., 2000; Schulze et al., 2006], and strengthen the evidence for familiality of these subphenotypes. Familial aggregation has also been observed in subphenotypes not included in the present study such as lithium-responsiveness [Grof et al., 1994], puerperal trigger of psychosis [Jones and Craddock, 2001], age of onset [Alda et al., 2000; Bellivier et al., 2003], and episode frequency [Fisfalen et al., 2005].

We saw evidence of familiality of suicide attempts and thoughts but not for other subphenotypes associated with depression. There are two previous reports of familality of traits associated with depression in bipolar families. Potash et al. [2000] found that suicide attempts clustered in families with BP and alcoholism. A recent report by Schulze et al. [2006] of 172 families with BP found evidence for familiality of depressive symptoms of suicide attempt, and suggested for suicide ideation and agitation/retardation.

We tested multiple subphenotypes and affection status models and therefore sought to evaluate our results in that context. The Bonferroni corrected $P$-value for evaluating analysis of the combined W1-4 data with inclusion of all covariates for 16 subphenotypes for Model 1 and for Model 3 is $0.05 /(16 \times 2)=0.0015$. This correction is likely conservative due to correlation between subphenotypes and the substantial overlap in individuals tested in Models 1 and 3. We observed a large excess of tests with $P$-values $<0.05,13$ of 32 subphenotype/affection models tested, and four tests with $P$-values less than the Bonferroni corrected value of 0.0015: psychosis in Model 1, alcoholism in Model 3, and rapid cycling in Models 1 and 3 suggesting strong evidence of familiality for these subphenotypes. The results for psychosis are more difficult to interpret because of the difference in familiality observed between $\mathrm{W} 1-2[\mathrm{OR}=0.76,95 \% \mathrm{CI}(0.41,1.42)]$ and $\mathrm{W} 3-4$ $[\mathrm{OR}=2.89,95 \% \mathrm{CI}(1.27,2.95)]$. The prevalence of psychosis did not differ between the waves so the reason for the difference in familiality is not clear.

Familiality of a subphenotype simply indicates that the subphenotype clusters within families and can be caused by a variety of factors. Biological reasons for familial clustering include a shared environment within families, shared predisposing genes, or an interaction between the shared environment and genes. Methods that test for familial aggregation of subphenotypes assume that the analyzed samples are representative of the underlying population, or that in the absence of representative sampling, factors which might cause stratification of the sample are included in the analysis. If factors that vary by family, such as site of interview, are not included in the analysis, and if the prevalence of the subphenotype differs between sites, the familial OR can show a positive association in the absence of true family clustering. We found substantial differences in subphenotype prevalence between sites in W3-4 and between waves (W1-2 vs. W3-4) within sites. Inclusion of site/wave of interview in the combined W1-4 analysis always diminished the family OR, at times causing the $P$-value to become several orders of magnitude less significant. This suggests that site and timing of interview should always be considered in analysis of multisite studies of psychiatric subphenotypes. 


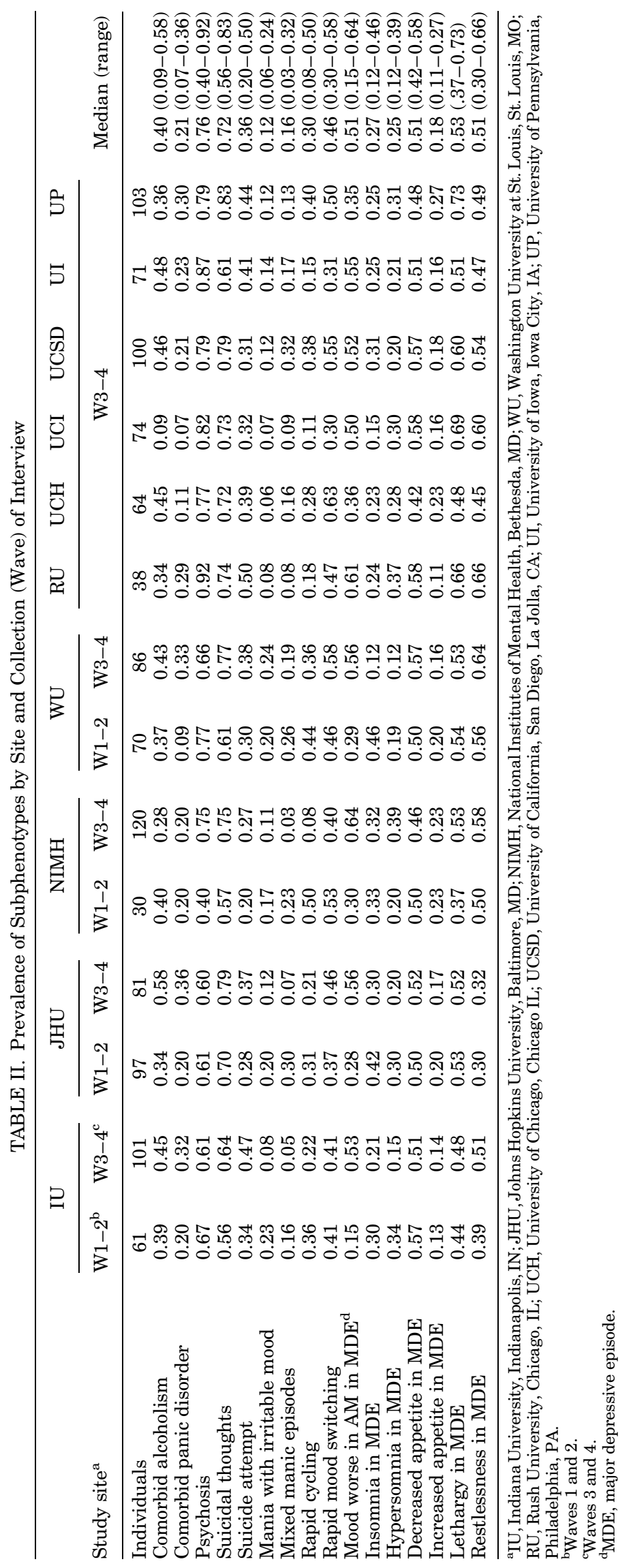


TABLE III. $P$-value for Heterogeneity of Subphenotype Prevalence by Collection Site and Wave

\begin{tabular}{|c|c|c|c|c|}
\hline & \multirow[b]{2}{*}{ Variability by wave $^{a}$} & \multicolumn{2}{|c|}{ Variability by site } & \multirow{2}{*}{$\begin{array}{l}\text { Variability by site/wave } \\
\text { of interview }^{b}\end{array}$} \\
\hline & & $\mathrm{W} 1-2$ & W3-4 & \\
\hline Comorbid alcoholism & $9.0 \times 10^{-3 *}$ & 0.70 & $5.5 \times 10^{-8}$ & $2.9 \times 10^{-7}$ \\
\hline Comorbid panic disorder & $1.2 \times 10^{-4}$ & 0.15 & $5.8 \times 10^{-6}$ & $1.8 \times 10^{-6}$ \\
\hline Psychosis & 0.51 & $2.0 \times 10^{-3}$ & $7.6 \times 10^{-4}$ & $8.8 \times 10^{-6}$ \\
\hline Suicidal thoughts & $1.5 \times 10^{-3}$ & 0.39 & 0.048 & $3.1 \times 10^{-3}$ \\
\hline Suicide attempt & 0.025 & 0.58 & 0.10 & 0.068 \\
\hline Mania with irritable mood & 0.042 & 0.93 & 0.16 & 0.020 \\
\hline Mixed manic episodes & $9.5 \times 10^{-6}$ & 0.42 & $2.9 \times 10^{-6}$ & $3.7 \times 10^{-9}$ \\
\hline Rapid cycling & $8.4 \times 10^{-6}$ & 0.25 & $2.0 \times 10^{-7}$ & $2.3 \times 10^{-9}$ \\
\hline Rapid mood switching & 0.32 & 0.34 & $5.2 \times 10^{-5}$ & $1.3 \times 10^{-4}$ \\
\hline Mood worse in AM in $\mathrm{MDE}^{\mathrm{c}}$ & $8.4 \times 10^{-12}$ & 0.17 & $1.5 \times 10^{-3}$ & $1.8 \times 10^{-11}$ \\
\hline Insomnia in MDE & $3.3 \times 10^{-5}$ & 0.19 & $8.7 \times 10^{-3}$ & $3.3 \times 10^{-5}$ \\
\hline Hypersomnia in MDE & 0.059 & 0.093 & $9.9 \times 10^{-4}$ & $1.1 \times 10^{-3}$ \\
\hline Decreased appetite in MDE & 0.55 & 0.44 & 0.58 & 0.70 \\
\hline Increased appetite in MDE & 0.38 & 0.43 & 0.36 & 0.47 \\
\hline Lethargy in MDE & 0.36 & 0.50 & $1.3 \times 10^{-3}$ & $1.1 \times 10^{-3}$ \\
\hline Restlessness in MDE & 0.055 & $4.3 \times 10^{-3}$ & $1.2 \times 10^{-2}$ & $1.1 \times 10^{-4}$ \\
\hline
\end{tabular}

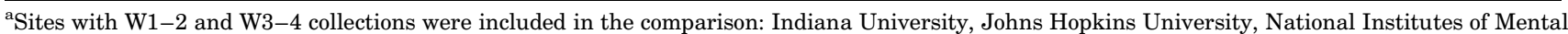
Health, Washington University of St. Louis.

${ }^{\mathrm{b}}$ For each collection at each site (14 collections).

${ }^{\mathrm{c}} \mathrm{MDE}$, major depressive episode.

$* P$-values $<0.05$ are shown in italic.

To our knowledge, the effect of site/wave of interview on the prevalence or familality of clinical measures has not been examined in this sample. Of the six previously reported studies of familiarity of subphenotypes studied here [Potash et al., 2000, 2001, 2003; MacKinnon et al., 2002, 2003a,b] two used data from multiple sites of the NIMHBGI [MacKinnon et al., $2002,2003 \mathrm{~b}]$. In $203 \mathrm{BP}$ families from the NIMHBGI, MacKinnon et al. [2002] demonstrated increased risk of panic disorder if probands had panic disorder using logistic regression with generalized estimating equation. In a subsequent study, MacKinnon et al. [2003b] discovered an association between familial clustering of rapid mood switching and panic disorder in 208 bipolar families from the NIMHBGI. Neither of the studies included site in the analysis, however, only data from NIMHBGI W1-2 was used, which showed little betweensite variation in prevalence of subphenotypes (Table III).

There was substantial between-site heterogeneity of subphenotype prevalence within the NIMHBGI sample. There are several factors that could contribute to heterogeneity. The interview sites were located in different regions of the United States and in both urban and rural settings. Site-specific differences in the participant's socioeconomic status could have affected the phenotype of illness and/or could have affected the recruitment of patients into the study. We considered the potential contribution of ethnicity, but did not see evidence that differences in self-identified ethnicity could account for between-site differences. The overall proportion of self-identified nonwhite individuals was $\sim 6 \%$ ( $\sim 3 \%$ Black/African-American). No site had over $16 \%$ selfidentified nonwhite enrollment and there were few and only very modestly significant differences in the prevalence of the subphenotypes by ethnicity, although differences would be difficult to detect because of the small size of the nonwhite sample (data not shown). In research involving clinical interviews and clinical judgment, bias could be introduced at several points in the process. Reporting of subphenotypes may be affected by the interviewer directing the clinical interview, the recording of information in the interview, and diagnostic patterns in the best-estimate process. We found that conducting interviews by telephone rather than in person did not account for site-specific significant differences in prevalence (data not shown).
For persecutory delusions, however, at two sites the prevalence was close to zero (data not shown). The data from those sites show persecutory delusion coded as zero, when in many cases there is text entered for the question describing the delusion. The data from the subtype of persecutory delusions were not included in our analysis due to this inconsistency, but suggests a possible reason for site-specific differences in prevalence. With the exception of persecutory delusions, we have not identified the source(s) of between-site subphenotype heterogeneity.

Even though we observed between-site heterogeneity, the overall prevalence of all but a few of the subphenotypes in our study are similar to those found in other samples such as the National Comorbidity Study [Kessler et al., 1997], the Epidemiological Cachment Area study [Regier et al., 1990], and meta-analysis reported in Goodwin and Jamison [1990]. Alcohol abuse or dependence, suicide attempts, diurnal variation in mood, lethargy and insomnia are slightly lower than reported rates; panic, suicidal thoughts and hypersomnia are slightly higher. Irritable mood in mania has been shown to be quite high, $80 \%$ in the meta-analysis in Goodwin and Jamison [1990]. Our rate of $12 \%$ likely differs because mood in the W1-2 study was characterized as either irritable or elated in a manic episode, and in many studies patients characterize mood as both irritable and elated. Mixed mania has been reported from $14-67 \%$ in different studies, and a metaanalysis has found the rate as high as $43 \%$ [Akiskal et al., $2000]$, but the rate in the NIMHBGI was only $16 \%$, perhaps due to differing definitions of mixed mania. With these exceptions, most subphenotypes had similar prevalence to other reported studies.

The similarity in subphenotype prevalence suggests that this sample is similar to samples collected without regard to family history and the more general bipolar population. Other features of the NIMHBGI study design support this conclusion. Our results are based on individuals from multiple sites, which after controlling for differences in subphenotype prevalence across sites, should increase the generalizability of our findings. This sample only includes individuals and their families who were willing to participate in research. It is difficult to know how individuals and families that chose not to participate differ from those who did. 


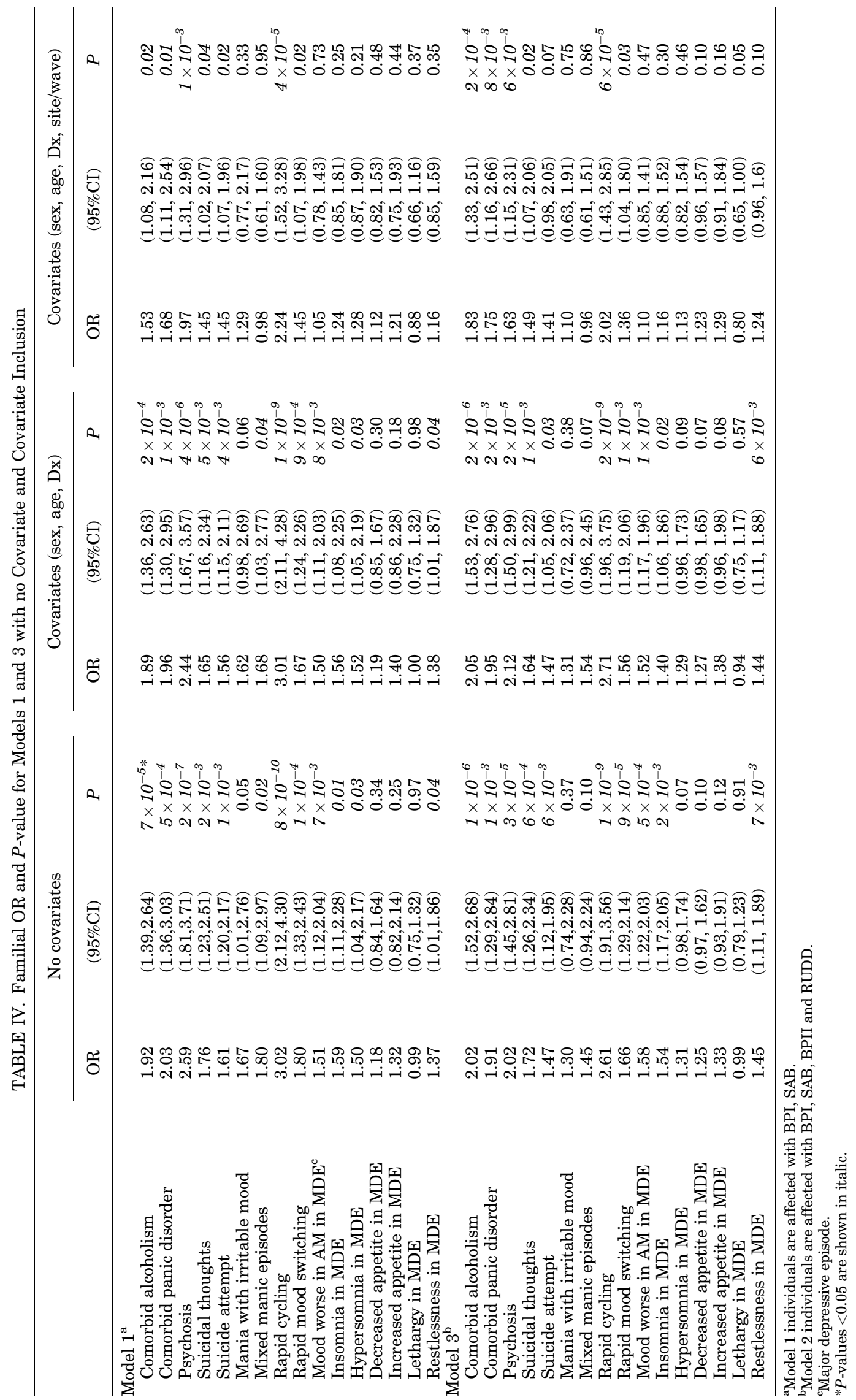




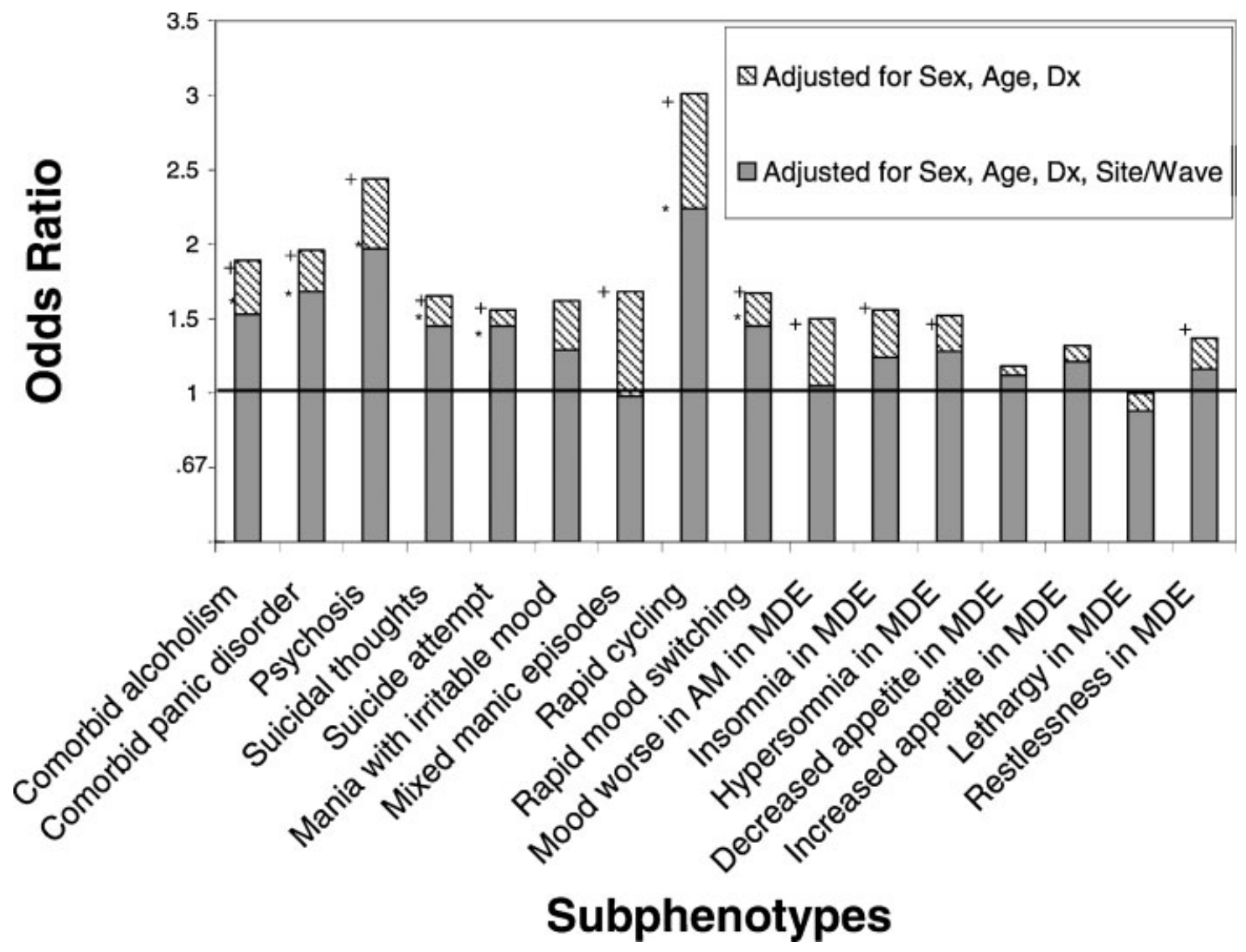

Fig. 1. Evidence for subphenotype aggregation in Model 1 sibships is decreased when site/wave is added as a covariate.,$+ P<0.05$ for models with age, sex, and Dx. * $P<0.05$ for models with age, sex, Dx, and site/wave of interview.

This analysis confirms and extends previous findings that comorbid alcohol abuse or dependence, comorbid panic disorder, psychosis, rapid cycling and rapid mood switching, suicidal thoughts and suicide attempts may be familial traits in BP families. We did not find familiality of depression-related symptoms of sleep disturbance, psychomotor disturbance, and mood worse in the morning or appetite increase or decrease. However, we observed that inclusion of site/wave of interview in our models often greatly attenuated our findings of familial clustering and suggest that it should be examined in any analysis that includes families from multisite studies. Our results provide a guide to subphenotypes that may have genetic underpinnings and could be used to subdivide individuals into more homogeneous groups within linkage or association studies. For each of these subphenotypes, this subdivision might lead to identification of genes that predispose specifically to the subphenotype or to genes that jointly increase the risk of BPI and the subphenotype.

\section{ACKNOWLEDGMENTS}

Data and biomaterials were collected as part of 10 projects that participated in the National Institute of Mental Health (NIMH) Bipolar Disorder Genetics Initiative. From 1999-03, the Principal Investigators and Co-Investigators were: Indiana University, Indianapolis, IN, R01 MH59545, John Nurnberger, M.D., Ph.D., Marvin J. Miller, M.D., Elizabeth S. Bowman, M.D., N. Leela Rau, M.D., P. Ryan Moe, M.D., Nalini Samavedy, M.D., Rif El-Mallakh, M.D. (at University of Louisville), Husseini Manji, M.D. (at Wayne State University),
Debra A. Glitz, M.D. (at Wayne State University), Eric T. Meyer, M.S., Carrie Smiley, R.N., Tatiana Foroud, Ph.D., Leah Flury, M.S., Danielle M. Dick, Ph.D., Howard Edenberg, Ph.D.; Washington University, St. Louis, MO, R01 MH059534, John Rice, Ph.D, Theodore Reich, M.D., Allison Goate, Ph.D., Laura Bierut, M.D.; Johns Hopkins University, Baltimore, MD, R01 MH59533, Melvin McInnis M.D., J. Raymond DePaulo, Jr., M.D., Dean F. MacKinnon, M.D., Francis M. Mondimore, M.D., James B. Potash, M.D., Peter P. Zandi, Ph.D, Dimitrios Avramopoulos, and Jennifer Payne; University of Pennsylvania, PA, R01 MH59553, Wade Berrettini M.D.,Ph.D.; University of California at Irvine, CA, R01 MH60068, William Byerley M.D., and Mark Vawter M.D.; University of Iowa, IA, R01 MH059548, William Coryell M.D., and Raymond Crowe M.D.; University of Chicago, IL, R01 MH59535, Elliot Gershon, M.D., Judith Badner Ph.D., Francis McMahon M.D., Chunyu Liu Ph.D., Alan Sanders M.D., Maria Caserta, Steven Dinwiddie M.D., Tu Nguyen, Donna Harakal; University of California at San Diego, CA, R01 MH59567, John Kelsoe, M.D., Rebecca McKinney, B.A.; Rush University, IL, R01 MH059556, William Scheftner M.D., Howard M. Kravitz, D.O., M.P.H., Diana Marta, B.S., Annette Vaughn-Brown, MSN, RN, and Laurie Bederow, MA; NIMH Intramural Research Program, Bethesda, MD, 1Z01MH002810-01, Francis J. McMahon, M.D., Layla Kassem, PsyD, Sevilla DeteraWadleigh, Ph.D, Lisa Austin, Ph.D, Dennis L. Murphy, M.D.

Most importantly, we thank the families who have participated in and contributed to these studies.

EHS was funded by R25MH063742, the Rachel Upjohn Clinical Scholars Program, the Heinz C. Prechter Pediatric Bipolar Scholars Program. 


\section{REFERENCES}

Akiskal HS, Bourgeois ML, Angst J, Post R, Moller H, Hirschfeld R. 2000. Reevaluating the prevalence of and diagnostic composition within the broad clinical spectrum of bipolar disorders. J Affect Disord 59 (Suppl 1):S5-S30.

Alda M. 2004. The phenotypic spectra of bipolar disorder. Eur Neuropsychopharmacol 14 (Suppl 2):S94-S99.

Alda M, Grof P, Ravindran L, Cavazzoni P, Duffy A, Grof E, Zvolsky P, Wilson J. 2000. Anticipation in bipolar affective disorder: Is age at onset a valid criterion? Am J Med Genet 96(6):804-880.

APA. 2000. Diagnostic and statistical manual of mental disorders: DSM-IV TR. Washington, DC: American Psychiatric Association. xxxvii:943 p

Badner JA, Gershon ES. 2002. Meta-analysis of whole-genome linkage scans of bipolar disorder and schizophrenia. Mol Psychiatry 7(4):405-411.

Bellivier F, Golmard JL, Rietschel M, Schulze TG, Malafosse A, Preisig M McKeon P, Mynett-Johnson L, Henry C, Leboyer M. 2003. Age at onset in bipolar I affective disorder: Further evidence for three subgroups. Am J Psychiatry 160(5):999-1001.

Bertelsen A, Harvald B, Hauge M. 1977. A Danish twin study of manicdepressive disorders. Br J Psychiatry 130:330-351.

Carey V, Zeger S, Diggle P. 1993. Modelling multivariate binary data with alternating logistic regressions. Biometrika 80:517-526.

Cassidy F, Forest K, Murry E, Carroll BJ. 1998. A factor analysis of the signs and symptoms of mania. Arch Gen Psychiatry 55(1):27-32.

Cassidy F, Ahearn EP, Carroll BJ. 2002. Symptom profile consistency in recurrent manic episodes. Compr Psychiatry 43(3):179-181.

Dick DM, Foroud T, Flury L, Bowman ES, Miller M.J, Rau NL, Moe PR Samavedy N, El-Mallakh R, Manji H, others. 2003. Genomewide linkage analyses of bipolar disorder: A new sample of 250 pedigrees from the National Institute of Mental Health Genetics Initiative. Am J Hum Genet 73(1):107-114

Fisfalen ME, Schulze TG, DePaulo JR, Jr, DeGroot LJ, Badner JA McMahon FJ. 2005. Familial variation in episode frequency in bipolar affective disorder. Am J Psychiatry 162(7):1266-1272.

Goodwin FK, Jamison KR. 1990. Manic-depressive illness. New York: Oxford University Press. xxi:938 p.

Grof P, Alda M, Grof E, Zvolsky P, Walsh M. 1994. Lithium response and genetics of affective disorders. J Affect Disord 32(2):85-95.

Hayden EP, Nurnberger JI, Jr. 2006. Molecular genetics of bipolar disorder Genes Brain Behav 5(1):85-95.

Jones I, Craddock N. 2001. Familiality of the puerperal trigger in bipolar disorder: Results of a family study. Am J Psychiatry 158(6):913-917.

Kessler RC, Rubinow DR, Holmes C, Abelson JM, Zhao S. 1997. The epidemiology of DSM-III-R bipolar I disorder in a general population survey. Psychol Med 27(5):1079-1089.

Korszun A, Moskvina V, Brewster S, Craddock N, Ferrero F, Gill M, Jones IR, Jones LA, Maier W, Mors O, et al. 2004. Familiality of symptom dimensions in depression. Arch Gen Psychiatry 61(5):468-474.

Liang K, Zeger S. 1986. Longitudinal data analysis using generalized linear models. Biometrika 73:13-22.

MacKinnon DF, Zandi PP, Cooper J, Potash JB, Simpson SG, Gershon E, Nurnberger J, Reich T, DePaulo JR. 2002. Comorbid bipolar disorder and panic disorder in families with a high prevalence of bipolar disorder. Am J Psychiatry 159(1):30-35.

MacKinnon DF, Zandi PP, Gershon E, Nurnberger JI, Jr, Reich T, DePaulo JR. 2003a. Rapid switching of mood in families with multiple cases of bipolar disorder. Arch Gen Psychiatry 60(9):921-928.

MacKinnon DF, Zandi PP, Gershon ES, Nurnberger JI, Jr, DePaulo JR, Jr $2003 \mathrm{~b}$. Association of rapid mood switching with panic disorder and familial panic risk in familial bipolar disorder. Am J Psychiatry 160(9):1696-1698.
McQueen MB, Devlin B, Faraone SV, Nimgaonkar VL, Sklar P, Smoller JW, Abou Jamra R, Albus M, Bacanu SA, Baron M, et al. 2005. Combined analysis from eleven linkage studies of bipolar disorder provides strong evidence of susceptibility loci on chromosomes $6 \mathrm{q}$ and 8q. Am J Hum Genet 77(4):582-595

NIMHBGI. 1997. Genomic survey of bipolar illness in the NIMH genetic initiative pedigrees: A preliminary report. Am J Med Genet 74(3):227237.

Nurnberger JI, Jr, Blehar MC, Kaufmann CA, York-Cooler C, Simpson SG, Harkavy-Friedman J, Severe JB, Malaspina D, Reich T. 1994 Diagnostic interview for genetic studies. Rationale, unique features, and training. NIMH Genetics Initiative. Arch Gen Psychiatry 5184951859 discussion 863-864.

Olfson M, Fireman B, Weissman MM, Leon AC, Sheehan DV, Kathol RG, Hoven C, Farber L. 1997. Mental disorders and disability among patients in a primary care group practice. Am J Psychiatry 154(12): 1734-1740

Parker G, Roy K, Mitchell P, Wilhelm K, Malhi G, Hadzi-Pavlovic D. 2002 Atypical depression: A reappraisal. Am J Psychiatry 159(9):1470_ 1479

Potash JB, Kane HS, Chiu YF, Simpson SG, MacKinnon DF, McInnis MG, McMahon FJ, DePaulo JR, Jr. 2000. Attempted suicide and alcoholism in bipolar disorder: Clinical and familial relationships. Am J Psychiatry 157(12):2048-2050.

Potash JB, Willour VL, Chiu YF, Simpson SG, MacKinnon DF, Pearlson GD DePaulo JR, Jr, McInnis MG. 2001. The familial aggregation of psychotic symptoms in bipolar disorder pedigrees. Am J Psychiatry 158(8):1258-1264.

Potash JB, Chiu YF, MacKinnon DF, Miller EB, Simpson SG, McMahon FJ, McInnis MG, DePaulo JR, Jr. 2003. Familial aggregation of psychotic symptoms in a replication set of 69 bipolar disorder pedigrees. Am J Med Genet Part B 116B(1):90-97.

Regier DA, Farmer ME, Rae DS, Locke BZ, Keith SJ, Judd LL, Goodwin FK. 1990. Comorbidity of mental disorders with alcohol and other drug abuse. Results from the Epidemiologic Catchment Area (ECA) Study. JAMA 264(19):2511-2518.

Reis I, Hirji K, Afifi A. 1999. Exact and asymptotic tests for homogeneity in several $2 \times 2$ tables. Stat Med 18:893-906.

Sato T, Bottlender R, Kleindienst N, Moller HJ. 2002. Syndromes and phenomenological subtypes underlying acute mania: A factor analytic study of 576 manic patients. Am J Psychiatry 159(6):968-974.

Sato T, Bottlender R, Sievas M, Schroter A, Hecht S, Moller HJ. 2003. Longterm inter-episode stability of syndromes underlying mania. Acta Psychiatr Scand 108(4):310-313.

Schulze TG, Hedeker D, Zandi P, Rietschel M, McMahon FJ. 2006. What is familial about familial bipolar disorder? Resemblance among relatives across a broad spectrum of phenotypic characteristics. Arch Gen Psychiatry 63(12):1368-1376.

Segurado R, Detera-Wadleigh SD, Levinson DF, Lewis CM, Gill M, Nurnberger JI, Jr, Craddock N, DePaulo JR, Baron M, Gershon ES, et al. 2003. Genome scan meta-analysis of schizophrenia and bipolar disorder, part III: Bipolar disorder. Am J Hum Genet 73(1):49-62.

Smoller JW, Finn CT. 2003. Family, twin, and adoption studies of bipolar disorder. Am J Med Genet C Semin Med Genet 123(1):48-58.

Sullivan PF, Prescott CA, Kendler KS. 2002. The subtypes of major depression in a twin registry. J Affect Disord 68(2-3):273-284.

Swann AC, Janicak PL, Calabrese JR, Bowden CL, Dilsaver SC, Morris DD Petty F, Davis JM. 2001. Structure of mania: Depressive, irritable, and psychotic clusters with different retrospectively-assessed course patterns of illness in randomized clinical trial participants. J Affect Disord 67(1-3):123-132.

WHO. 2001. The World Health Report: 2001: Mental health: New understanding, new hope. Geneva: World Health Organization. 169 p. 